\title{
Grape Phenolic Extract Potentially Useful in the Control of Antibiotic Resistant Strains of Campylobacter
}

\author{
Elisa Mingo ${ }^{1}$, Alfonso V. Carrascosa ${ }^{1}$, Sonia de Pascual-Teresa ${ }^{2}$, \\ Adolfo J. Martinez-Rodriguez ${ }^{{ }^{*}}$ \\ ${ }^{1}$ Instituto de Investigación en Ciencias de la Alimentación (CIAL), CSIC-UAM, Departamento de Biotecnología y Microbiología. \\ C/Nicolás Cabrera, 9. Cantoblanco Campus, Universidad Autónoma de Madrid, Madrid, Spain \\ ${ }^{2}$ Instituto de Ciencia y Tecnología de Alimentos y Nutrición (ICTAN), CSIC, Departamento de Metabolismo \\ y Nutrición-C/Jose Antonio Novais, Madrid, Spain \\ Email: ${ }^{*}$ adolfo.martinez@csic.es
}

Received November 7, 2013; revised December 7, 2013; accepted December 14, 2013

Copyright (C) 2014 Elisa Mingo et al. This is an open access article distributed under the Creative Commons Attribution License, which permits unrestricted use, distribution, and reproduction in any medium, provided the original work is properly cited. In accordance of the Creative Commons Attribution License all Copyrights (C) 2014 are reserved for SCIRP and the owner of the intellectual property Elisa Mingo et al. All Copyright (C) 2014 are guarded by law and by SCIRP as a guardian.

\begin{abstract}
In this work, a grape phenolic extract obtained by methanol extraction has been demonstrated to be effective in inhibiting the growth of different strains and species of Campylobacter, one of the most important bacterial foodborne pathogens causing gastroenteritis worldwide. Noteworthily, it was particularly effective against several strains presenting multiple antibiotic resistances. In all cases, the minimum inhibitory concentration (MIC) was lower than $300 \mathrm{mg} \mathrm{GAE} / \mathrm{L}$, being of $60 \mathrm{mg}$ GAE/L for one of the most resistant strains (C. coli LP2), while the others were between $120 \mathrm{mg}$ GAE/L and $180 \mathrm{mg} \mathrm{GAE} / \mathrm{L}$. The analytical study of the main phenolic compounds in the grape extract revealed that it was mainly constituted by catechins $(\mathbf{8 5 . 7 \% )}$ ) and phenolic acids $(\mathbf{1 3 . 7 \% )}$. However, experiments developed using pure standards demonstrate that phenolic acids (such as gallic, p-hidroxibenzoic, vanillic, and homovanillic acids) were the most active, provoking a Campylobacter growth decrease between 6.7 and $7.6 \mathrm{log}$, while epicatechin was the only catechin with activity as pure compound (1 log of growth decrease).
\end{abstract}

\section{KEYWORDS}

Campylobacter; Food-Borne Pathogen; Antibiotic Resistance; Grape Phenolic Extract; Phenolic Acids; Flavanols

\section{Introduction}

Campylobacter species are the leading causes of bacterial food-borne gastroenteritis worldwide and the species Campylobacter jejuni (C. jejuni) and Campylobacter coli (C. coli) cause more than $95 \%$ of the infections attributed to this genus [1]. Campylobacter infections in humans are usually characterized by self-limiting diarrhea, abdominal cramps, nausea and fever, but severe neurological sequelae, bacteremia, and other extraintestinal complications may develop less frequently [2]. Several sources of Campylobacter infection in humans have been suggested, but the most common is mainly associated with the consumption and/or handling of poultry meat, especially

${ }^{*}$ Corresponding author. fresh broiler meat [3]. Although most infections are resolved without specific treatment, antimicrobial therapy can be critical in invasive or severe infections. Fluoroquinolone agents, like ciprofloxacin and macrolides such as erythromycin, are commonly used for the treatment of infections caused by Campylobacter [4]. However, the rise in the incidence of infections caused by antibiotic-resistant strains of Campylobacter makes this illness increasingly difficult to treat [5]. Moreover, since a large proportion of the European Union (EU) chicken production is contaminated with the pathogen [6] and given the recent ban by the European Union on the use of antibiotics in animal feed to promote growth [7], it is essential to search for new, natural and sustainable strategies to reduce the incidence of Campylobacter in the food chain, especially in its main host. Consumer concerns about the 
safety of food have increased, and in this regard, there is a growing interest in the use of natural antibacterial compounds, like plant extracts rich in phenolic compounds, as food preservatives. In the last years, different works about the antimicrobial properties of wine and grape phenolic compounds have been published, and several studies have shown that these compounds could inhibit the growth of different food-borne bacteria [8,9]. Concerning Campylobacter, other researchers have reported that some phenolic compounds from grape leaves can have antimicrobial activity against this pathogen [10], contributing to modulating the resistance to macrolide antibiotics [11]. We have previously reported the antimicrobial activity of a commercial extract of GSE against Campylobacter, identifying the main phenolic compounds related with the behavior observed [12]. In this work, we have obtained several grape extracts using two solvents (methanol and water). The most active extract has been selected to study its antibacterial activity against different species and strains of Campylobacter, identifying the main compounds responsible for the antibacterial activity. The bactericidal effect was compared to that of 10 different antibiotics, with the purpose of establishing the potential of grape phenolic compounds in the control of Campylobacter.

\section{Materials and Methods}

\subsection{Bacterial Strains, Growth Media, and Culture Conditions}

The microorganisms used in this study included 12 different strains: 9 of $C$. jejuni and 3 of $C$. coli. Strain specification and origin of the specimen is provided in Table 1.

Table 1. Source of Campylobacter species obtained from veterinary, clinical and collection libraries. La Paz and Carlos III are hospitals of Madrid, Spain.

\begin{tabular}{cccc}
\hline Specie & Strain & Origin & Source \\
\hline \multirow{2}{*}{$\begin{array}{c}\text { Campylobacter } \\
\text { jejuni }\end{array}$} & LP1 & Clinical & La Paz \\
& 11168 & Collection & NCTC $^{\text {a }}$ \\
& 118 & Clinical & Carlos III \\
& 11351 & Collection & NCTC \\
& CIII & Clinical & Carlos III \\
& CN1 & Veterinary & CIAL \\
& CNL1 & Veterinary & CIAL \\
& CNL2 & Veterinary & CIAL \\
& 7572 & Collection & CECT \\
& & & \\
Campylobacter & LP2 & Clinical & La Paz \\
& CNL4 & Veterinary & CIAL \\
& 7571 & Collection & CECT
\end{tabular}

${ }^{\mathrm{a}}$ Bacterial cultures obtained from the National Collection of Types Cultures (NCTC), UK, ${ }^{\mathrm{b}}$ Collection from Instituto de Investigación en Ciencias de la Alimentación, (CIAL), 'Spanish Collection of Type Cultures (CECT).
All strains were stored at $-80^{\circ} \mathrm{C}$. Liquid growth medium for Campylobacter strains consisted of Brucella Broth (BB) (Becton, Dickinson, \& Company, New Jersey, USA). The agar plating medium consisted of Müeller-Hinton agar supplemented with 5\% defibrinated sheep blood (MHB) (Becton, Dickinson, \& Company). The frozen strains were reactivated by inoculation in MHB and incubation under microaerophilic conditions $\left(85 \% \mathrm{~N}_{2}\right.$, $10 \% \mathrm{CO}_{2}, 5 \% \mathrm{O}_{2}$ ) using a Variable Atmosphere Incubator (VAIN) (MACS-VA500) (Don Whitley Scientific, Shipley, UK) at $42^{\circ} \mathrm{C}$ for $48 \mathrm{~h}$. Isolated colonies were inoculated into $50 \mathrm{ml}$ of $\mathrm{BB}$ and incubated under stirring at $130 \mathrm{rpm}$ on an orbital shaker (Shaker S3) (Elmi, Riga, Latvia) at $42^{\circ} \mathrm{C}$ for $24 \mathrm{~h}$ in microaerophilic conditions in the VAIN. These bacterial inocula cultures $(\sim 1 \times 108$ $\mathrm{CFU} / \mathrm{ml}$ ) were used for the antibacterial activity assays.

\subsection{Antibiotic Susceptibility Testing}

The antibiotic susceptibility was assessed for each strain following the Kirby-Bauer disc diffusion method based on the performance standards for antimicrobial disk susceptibility test [13]. The bacterial inoculum in BB was spread onto MHB using sterile cotton-tipped swabs. Antimicrobial discs (Oxoid, Basingstoke, UK) were placed on the inoculated MHB plates and they were incubated in the VAIN for $48 \mathrm{~h}$. The following antimicrobial discs were used: aztreonam, tetracycline, gentamicin, cephalothin, amoxicillin-clavulanic acid, nalidixic acid, chloramphenicol, erythromycin (all $30 \mu \mathrm{g})$, streptomycin (25 $\mu \mathrm{g}$ ), and ciprofloxacin $(5 \mu \mathrm{g})$. Interpretation of the results was performed using the resistance breakpoint for Campylobacters described by others [14,15]. When no breakpoints were available for Campylobacters, the resistance breakpoint described by CLSI for Enterobacteriaceae was used. The breakpoints are shown in Table 2.

\subsection{Grape Extracts Preparation}

Phenolic extracts were prepared from three varieties of Vitis vinifiera grapes: Tempranillo, Garnacha and Cabernet Sauvignon. Extraction and concentration of the phenolic fraction was carried out by the procedure described by Pallauf et al. [16]. Two different solvents were used in the extraction process: methanol, as non-polar solvent, and water (polar solvent).

Briefly, fresh grapes were homogenized using an Ultra-Turrax T25 (IKA-WERKE GmbH \& Co., Staufen, Germany) for 2 - 3 min. to obtain 100 g of grape's homogenated. $100 \mathrm{ml}$ of methanol 100\% (Sigma-Aldrich, Missouri, USA) or water was added to the homogenate and mixed for 15 min. Afterwards, it was centrifuged for 10 min. at $4500 \mathrm{rpm}$ and the supernatant was collected. The extraction process was repeated twice more. 
Table 2. Breakpoints for Campylobacter spp.

\begin{tabular}{ccccc}
\hline Antibiotic & Potency & R & I & S \\
\hline Gentamicin $^{* * *}$ & $10 \mu \mathrm{g}$ & $\leq 12$ & $13-14$ & $\geq 15$ \\
Cephalotin $^{* * *}$ & $30 \mu \mathrm{g}$ & $\leq 14$ & $15-17$ & $\geq 18$ \\
Streptomycin $^{* * *}$ & $10 \mu \mathrm{g}$ & $\leq 10$ & $11-12$ & $\geq 15$ \\
Tetracyclin $^{* *}$ & $30 \mu \mathrm{g}$ & $\leq 14$ & $15-18$ & $\geq 19$ \\
Cloramphenicol $^{*}$ & $30 \mu \mathrm{g}$ & $\leq 11$ & $12-22$ & $\geq 23$ \\
Eritromycin $^{*}$ & $15 \mu \mathrm{g}$ & $\leq 15$ & $16-18$ & $\geq 19$ \\
Aztreonam $^{* * *}$ & $30 \mu \mathrm{g}$ & $\leq 15$ & $16-21$ & $\geq 22$ \\
Nalidixic Acid $^{* *}$ & $30 \mu \mathrm{g}$ & $\leq 13$ & $14-18$ & $\geq 19$ \\
Ciprofloxacin $^{*}$ & $20 / 10 \mu \mathrm{g}$ & $\leq 13$ & $14-17$ & $\geq 18$ \\
$\begin{array}{c}\text { Amoxicillin } \\
\text { Clavulanic Acid }\end{array}$ & $5 \mu \mathrm{g}$ & $\leq 18$ & $19-23$ & $\geq 24$ \\
\hline${ }^{*}$ Miflin et al. (2007), ${ }^{* *}$ Luangtongkum et al. $(2007),{ }^{* * *}$ Clinical Laboratory \\
Standards Institute (CLSI) (2007). & & &
\end{tabular}

The extracts were then combined, filtered through a Büchner funnell and concentrated by evaporation at $30^{\circ} \mathrm{C}$ (Rotavapor ${ }^{\circledR} 210$ R-210 BÜCHI) (Labortechnik AG, Flawil, 211 Switzerland). The extract obtained in each case was suspended in $100 \mathrm{ml}$ of water. The resulting aqueous extracts were then lyophilized and the powder stored at $-20^{\circ} \mathrm{C}$

\subsection{Antibacterial Activity of the Grape Extract}

A first screening was performed to analyze the antibacterial activity of the different grape extracts (Tempranillo, Garnacha and Cabernet Sauvignon) against C.jejuni LP1. The extract which showed the strongest antibacterial activity was then selected for the following experiments with antibiotic-resistant strains. In all cases we used the following quantitative procedure: $1 \mathrm{ml}$ of sample was transferred into different flasks containing $4 \mathrm{ml}$ of BB. Bacterial inocula (50 $\mu \mathrm{l}$ with 1x108 colony forming units $\mathrm{x}$ mililiter (CFU/ml) were then inoculated into the flasks under aseptic conditions. All cultures were prepared in triplicate and incubated microaerobically at $42^{\circ} \mathrm{C}$ for $24 \mathrm{~h}$ (130 rpm) in the VAIN. Positive growth controls were prepared by transferring $1 \mathrm{ml}$ of saline solution $(\mathrm{NaCl}$ $0.9 \%$ ) to $4 \mathrm{ml}$ of BB and $50 \mu \mathrm{l}$ of bacterial inocula. After incubation, serial decimal dilutions of mixtures were prepared in saline solution and they were plated $(10 \mu \mathrm{l})$ onto fresh MHB agar and incubated microaerobically at $42^{\circ} \mathrm{C}$ in the VAIN. The number of CFU was assessed after $48 \mathrm{~h}$ of incubation. Results were expressed as log $\mathrm{CFU} / \mathrm{ml}$. The minimal inhibitory concentration (MIC) and the minimal bactericidal concentration (MBC) were determined following the procedure described above and by using each grape extract diluted in sterile water to obtain the desired final concentration. MIC was defined as the lowest concentration of sample that provokes a statistically significant decrease in viability with respect to the control growth after $24 \mathrm{~h}$ of treatment. MBC was defined as the lowest concentration of sample where no growth was observed after $24 \mathrm{~h}$ of treatment.

\subsection{Assessment of Total Phenolic Content (TPC)}

The total phenolic content (TPC) in the different grape extracts was determined in accordance with the FolinCiocalteu micro method as previously described by Schmidt et al. [17]. Briefly, samples ( $10 \mu \mathrm{l})$ were added to a 96-well microtiter plate (Sarstedt, Nümbrecht, Germany) at an adequate dilution in triplicate. To start the reaction, $150 \mu \mathrm{l}$ of aqueous Folin-Ciocalteu (Sigma-Aldrich) solution (14 ml water to $1 \mathrm{ml}$ of Folin-Ciocalteu reagent) was added to each well. After 3 minutes, $50 \mu$ of $\mathrm{NaHCO}_{3}$ solution (2 $\mathrm{ml}$ of saturated $\mathrm{NaHCO}_{3}$ to $3 \mathrm{ml}$ of water) was added to each well and the plate was placed in the dark at room temperature for $2 \mathrm{~h}$. Absorbance was measured at $725 \mathrm{~nm}$ using a BioTek Synergy HT Multi-Mode microplate reader (BioTek Instruments Inc., Vermont, USA), and the data were acquired and processed using BioTek's Gen5TM software (BioTek Instruments Inc.). Gallic acid (Sigma-Aldrich) was used as the standard for a calibration curve. TPC was expressed as milligrams of gallic acid equivalents per liter (mg GAE/L).

\subsection{Determination of Individual Phenolic Compounds of the Extracts by HPLC and Mass Spectrometry Detection}

All HPLC analyses were carried out on a Hewlett-Packard Agilent 1200 Series liquid chromatography system equipped with a quaternary pump and a photodiode array detector (DAD) (Agilent Technologies, Waldrom, Germany). The column used was a Phenomenex Luna C18 column $(4.6 \times 150 \mathrm{~mm}, 5 \mu \mathrm{m})$ (Phenomenex, California, USA) which was set thermostatically at $25^{\circ} \mathrm{C}$. Chromatographic data were acquired and processed using an Agilent Chemstation for LC 3D system (Rev. B.04.01) (Agilent Technologies). The HPLC method conditions were as described by Avila et al. [18]. Briefly, the binary mobile phase used for analyses were aqueous $4.5 \%$ formic acid (A) and HPLC-grade acetonitrile (B) at a flow rate of $0.5 \mathrm{ml} / \mathrm{min}$. The elution started with $10 \% \mathrm{~B}$, and the gradient was $20 \%$ B from 0 to $20 \mathrm{~min}, 25 \% \mathrm{~B}$ from 20 to $30 \mathrm{~min}$, and $35 \%$ B from 30 to $50 \mathrm{~min}$. Detection wavelengths were 280, 320, 440 and $520 \mathrm{~nm}$ and samples were analyzed in triplicate. Peaks were identified by comparing their retention time and UV-vis spectra with the reference compounds, and the data were quantified using the corresponding curves of the reference compounds as standards. In order to confirm the identity of 
the recorded compounds, additional analyses were performed by using HPLC with mass spectrometry detection (HPLC-MS). For mass spectrometry an Agilent 1100 series liquid chromatograph/mass-selective detector equipped with a quadrupole (G1946D) mass spectrometer (Agilent Technologies) was used. Separation was achieved with an ORBAX Eclipse XDB-C18, (4.6 × 150 mm, 5 $\mu \mathrm{m})$ (Agilent Technologies). Elution was performed with a gradient between $2.5 \%$ acetic acid in Milli-Q water (solution A), a mixture of $2.5 \%$ acetic acid in Milli-Q and water-acetonitrile (90:10) (solution B), and pure acetonitrile (solution $\mathrm{C}$ ) at a flow rate of $0.5 \mathrm{ml} / \mathrm{min}$, and an injection volume of $20 \mu \mathrm{l}$. The elution programme consisting of the following: from $100 \% \mathrm{~A}$ to $100 \% \mathrm{~B}$ in $3 \mathrm{~min}$, from $100 \%$ to $93 \% \mathrm{~B}$ in $5 \mathrm{~min}$, from $7 \%$ to $10 \% \mathrm{C}$ in 7 min, from $10 \%$ to $15 \%$ C in 5 min, from $15 \%$ to $50 \%$ C in $5 \mathrm{~min}$ and isocratic 50\% C and B for another $5 \mathrm{~min}$. Electrospray ionisation in the positive mode was used. The electrospray capillary voltage was set to $2500 \mathrm{~V}$, with a nebulising gas flow rate of 12 liters/min and a drying gas temperature of $150^{\circ} \mathrm{C}$.

\subsection{Antimicrobial Activity Assay of Pure Phenolic Compounds}

The phenolic compounds identified in the most active extract were tested against $C$. jejuni LP1 as pure compounds. The assayed compounds (quercetin, quercetin 3glucoside, homovanillic acid, vanillic acid, gallic acid, protocatechuic acid, clorogenic acid, p-hidroxibenzoic acid, sinapic acid, catechin, epicatechin, and procyanidins B1, B2 were purchased from Sigma-Aldrich). The procedure used has been described above. CFU was assessed after $48 \mathrm{~h}$ of incubation. Results were expressed as $\log \mathrm{CFU} / \mathrm{ml}$.

\subsection{Statistical Analysis}

Analysis of variance (ANOVA) was performed by SPSS 19.0 for Windows, version 19.0.0 (Dec. 2011).

\section{Results and Discussion}

\subsection{Antibiotic Susceptibility Test for Campylobacter spp.}

The results of the antibiotic susceptibility test are shown in Table 3. The sensitivity to antibiotics was dependent on the Campylobacter strain. Strains from international culture collections (11168, 11351, 7572 and 7571) were the most sensitive, presenting from null to 2 antibiotic resistances. On the other hand, recent isolates from clinical (LP2) and veterinary origin (CN1 and CNL4) were resistant to five antibiotics. Among antibiotics, the high percentage of resistances were found in ciprofloxacin (66.6\%) and nalidixic acid (58.3\%), both of them of the fluoroquinolones group, whereas all strains tested were sensitive to aminoglucosides (streptomycin and gentamicin), chloramphenicol and amoxicillin/clavulanic acid. It is known that bacteria often lose virulence by growth in vitro, and that the genetics basis for virulence may be expressed completely only during growth in vivo. This fact has been observed for Campylobacters, where the comparation of the transcriptional profile of the original clonal isolate of $C$. jejuni 11168 and the genome-sequenced clone of $C$. jejuni 11168 showed important differences in gene expression [19]. Also, the use of repeatedly subcultured strains of Helicobacter pylori ( $H$. pylori), a close-related microorganism, in virulence experiments, has shown the loss of several virulence properties respect to the original strain [20]. These results demonstrate the effect of laboratory culture and storage on virulence properties, suggesting the importance to use strains with low subcultures in studies of virulence and/ or sensitivity to drugs. The behavior against fluoroquinolones has confirmed the striking increase in resistance of Campylobacter against these drugs in the last years, rendering now in a limited use of them in the treatment of campilobacteriosis in many regions [2]. Only C. coli (LP2) was resistant to erythromycin, one of the first choices in the antibiotic treatment of campilobacteriosis due to its low resistance rates ( $0 \%$ to $12 \%)$, although it is generally higher in C. coli, ranging from $0 \%$ to $50 \%$ [21]. Even if the majority of $C$. jejuni and $C$. coli are resistant to $\beta$ lactam agents, amoxicillin plus clavulanic acid has already been reported as effective [22], in accordance with the results obtained in the present work. Other drugs such as tetracycline and chloramphenicol can be alternative antibiotics, but up to $60 \%$ of strains may be resistant to tetracycline [23].

In the last years, it has been found that some compounds derived from plants can be active against antibiotic-resistant pathogens associated with foods, possibly by using different mechanisms of action [24]. For this reason, in the present work we evaluate the effect of three different grape extracts against Campylobacter in order to clarify its possible use as an antimicrobial.

\subsection{Antibacterial Effect of Grape Extracts on Campylobacter spp.}

The results of the antibacterial activity of the different grape extracts against $C$. jejuni LP1 showed that phenolic extraction using methanol as solvent (average 4.56 log of growth inhibition) was more effective than the extraction with water (average 1.91 log of growth inhibition) (Table 4). This is consistent with the total phenolic content (TPC) determined for each extract, which showed that the amount of phenolic compounds extracted using methanol was higher than the one obtained with water 
Table 3. Antimicrobial susceptibility profile for the Campylobacter spp. strains by Kirby-Bauer disc diffusion method.

\begin{tabular}{|c|c|c|c|c|c|c|c|c|c|c|c|c|}
\hline Antibiotic & LP1 & 1168 & 118 & 11351 & CIII & CN1 & CNL1 & CNL2 & 7571 & LP2 & CNL4 & 7572 \\
\hline Gentamicin & S & S & S & S & S & S & S & S & S & S & S & S \\
\hline Cephalotin & S & $\mathbf{R}$ & $\mathbf{R}$ & $\mathbf{R}$ & $\mathbf{R}$ & $\mathbf{R}$ & $\mathbf{R}$ & $\mathbf{R}$ & S & $\mathbf{R}$ & $\mathbf{R}$ & $\mathbf{R}$ \\
\hline Streptomycin & S & S & S & S & S & S & S & S & S & S & S & S \\
\hline Tetracyclin & I & S & S & S & I & $\mathbf{R}$ & $\mathbf{R}$ & $\mathbf{R}$ & S & I & $\mathbf{R}$ & $\mathrm{S}$ \\
\hline Chloramphenicol & S & S & S & S & S & S & S & S & S & S & S & $\mathrm{S}$ \\
\hline Eritromycin & S & S & S & S & S & S & S & S & S & $\mathbf{R}$ & S & $\mathrm{S}$ \\
\hline Aztreonam & S & S & S & $\mathbf{R}$ & $\mathbf{R}$ & $\mathbf{R}$ & S & S & S & $\mathbf{R}$ & $\mathbf{R}$ & $\mathbf{R}$ \\
\hline Nalidixic Acid & $\mathbf{R}$ & S & $\mathbf{R}$ & S & S & $\mathbf{R}$ & $\mathbf{R}$ & $\mathbf{R}$ & S & $\mathbf{R}$ & $\mathbf{R}$ & S \\
\hline Ciprofloxacin & $\mathbf{R}$ & S & $\mathbf{R}$ & S & $\mathbf{R}$ & $\mathbf{R}$ & $\mathbf{R}$ & $\mathbf{R}$ & S & $\mathbf{R}$ & $\mathbf{R}$ & $\mathrm{S}$ \\
\hline Amoxicillin-Clavulanic Acid & S & S & $S$ & $S$ & $S$ & $S$ & $S$ & S & $S$ & S & S & $S$ \\
\hline
\end{tabular}

S: susceptible; R: resistant; I: intermediate.

Table 4. Antibacterial activity of three different grape extracts against $C$. jejuni LP1. Three varieties of grapes (Cabernet Sauvignon, Garnacha and Tempranillo) were tested, and two different extractions were obtained (methanolic or water) for each grape variety. The results are expressed in $\mathrm{Log}$ CFU/ml \pm standard deviation (SD) $(\mathrm{n}=3)$.

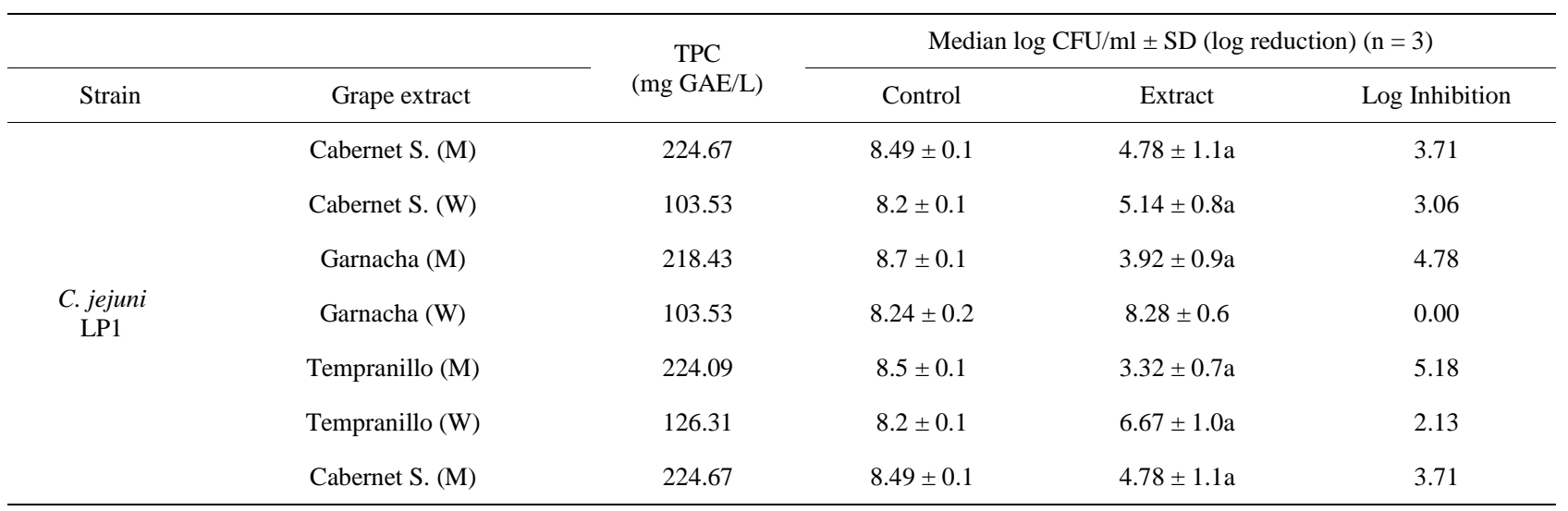

coinciding with the reported by others [25]. However, no differences were observed in the individual phenolic compounds extracted, which were the same independently of the extraction method used (data not shown). Among the methanolic extracts, the most effective was the Tempranillo extract. Thus, we selected it for next series of experiments.

The results of the antibacterial activity of the selected grape extract against different Campylobacter strains are presented in Table 5. For this assay, the five most resistant strains (with 4 or 5 antibiotic resistances) were used and the clinical isolate LP1 (with 2 antibiotic resistances) was also included. With the purpose to determine the lower concentration of the grape extract able to inhibit Campylobacter growth we calculated the MIC and MBC for each strain. The results obtained showed a relationship between strain and sensitivity. In all cases, the MIC was lower than $300 \mathrm{mg}$ GAE/L, being the lowest value of
$60 \mathrm{mg}$ GAE/L for C. jejuni LP1 (two antibiotic resistances) and C. coli LP2 (five antibiotic resistances). The MIC for the other strains was $120 \mathrm{mg} \mathrm{GAE} / \mathrm{L}$ (C. jejuni CN1, CNL1, and CNL2) and $180 \mathrm{mg} \mathrm{GAE/L} \mathrm{for} \mathrm{C.} \mathrm{coli}$ CNL4. The MBC was between $240 \mathrm{mg} \mathrm{GAE} / \mathrm{L}$ and 120 mg GAE/L, showing a similar behavior as MIC. In general terms the extract showed a strong capacity to inhibit Campylobacter growth regardless of the Campylobacter species (C. jejuni or $C$. coli) or the origin of the strain (human or veterinary). These MIC and MBC values seem relevant, taking into account that they are below 100 $\mathrm{mg} / \mathrm{L}$ [26].

\subsection{Phenolic Composition of the Grape Extract}

In Table 6 are shown the main individual phenolic compounds identified in the Tempranillo grape extract. The main group of phenolic compounds in the extract consisted of catechins (85.7\%) and phenolic acids (13.7\%). 
Table 5. MIC and MBC of the Tempranillo grape extract against different antibiotic resistant strains of Campylobacter spp. The results are expressed in $\mathrm{Log} \mathrm{UFC} / \mathrm{ml} \pm$ standard deviation (SD) $(\mathrm{n}=2)$.

\begin{tabular}{ccccccc}
\hline \multicolumn{7}{c}{ Median log CFU/ml \pm SD $(\log$ reduction) $(\mathbf{n}=2)$} \\
\hline $\begin{array}{c}\text { Concentration of the grape } \\
\text { phenolic extract (mg GAE/L) }\end{array}$ & & \multicolumn{5}{c}{ Campylobacter strain } \\
\cline { 2 - 7 } & C. jejuni LP1 & C. jejuni CNL1 & C. jejuni CN1 & C. jejuni CNL2 & C. coli LP2 & C. coli CNL4 \\
\hline Control & $7.89 \pm 0.2$ & $8.04 \pm 0.2$ & $8.45 \pm 0.2$ & $8.39 \pm 0.1$ & $7.54 \pm 0.2$ & $8.01 \pm 0.2$ \\
300 & $>1.48 \mathrm{a} \pm 0.0$ & $>1.48 \mathrm{a} \pm 0.0$ & $>1.48 \mathrm{a} \pm 0.0$ & $>1.48 \mathrm{a} \pm 0.0$ & $>1.48 \mathrm{a} \pm 0.0$ \\
240 & $>1.48 \mathrm{a}^{*} \pm 0.0$ & $>1.48 \mathrm{a} \pm 0.0$ & $>1.48 \mathrm{a} \pm 0.0$ & $>1.48 \mathrm{a} \pm 0.0^{* * *}$ & $>1.48 \mathrm{a} \pm 0.0$ & $>1.48 \mathrm{a} \pm 0.0^{* *}$ \\
180 & $>1.48 \mathrm{a} \pm 0.0$ & $5.38 \mathrm{a} \pm 0.0^{* * *}$ & $6.45 \mathrm{a} \pm 0.7^{* *}$ & $6.75 \mathrm{a} \pm 0.1^{* *}$ & $>1.48 \mathrm{a} \pm 0.0^{* * *}$ & $7.70 \pm 0.1$ \\
120 & $>1.48 \mathrm{a} \pm 0.0$ & $8.40 \pm 0.8$ & $8.40 \pm 0.1$ & $8.49 \pm 0.7$ & $7.13 \mathrm{a} \pm 1.0^{* *}$ & $7.95 \pm 0.2$ \\
60 & $>1.48 \mathrm{a} \pm 0.0^{* * *}$ & $8.77 \pm 0.2$ & $8.70 \pm 0.0$ & $8.29 \pm 1.1$ & $8.65 \pm 0.2$ & $8.17 \pm 0.0$ \\
30 & $2.77 \mathrm{a} \pm 1.2^{* *}$ & $8.58 \pm 0.2$ & & & & \\
\hline
\end{tabular}

${ }^{*}$ Calculated log of detection limit (30 CFU per plate). ${ }^{* *}$ Minimal Inhibitory Concentration (MIC), ${ }^{* * *}$ Minimal Bactericidal Concentration (MBC), a significantly different with respect to the growth control ( $\mathrm{p} \leq 0.05$ ).

Table 6. Individual phenolic composition (mg/L) of the Tempranillo grape extract (mean \pm standard deviation) $(n=3)$ determined by HPLC-MS.

\begin{tabular}{ccc}
\hline Family & Compound & Concentration (mg/L) \\
\hline Flavonols & Quercetin-3-glucoside & $4 \pm 0.0$ \\
Phenolic Acids & Quercetin & $7 \pm 0.0$ \\
& Gallic Acid & $37 \pm 0.1$ \\
& Homogentisic Acid & $21 \pm 0.0$ \\
& Protocatechuic Acid & $27 \pm 7.0$ \\
& Chlorogenic Acid & $6 \pm 0.1$ \\
& Homovanillic Acid & $72 \pm 4.6$ \\
& Vanillic Acid & $41 \pm 2.0$ \\
& p-cumaric Acid & $12 \pm 0.0$ \\
Catechins & p-Hidroxibenzoic Acid & $21 \pm 1.6$ \\
& Sinapic Acid & $31 \pm 1.0$ \\
& Catechin (cat) & $680 \pm 4.4$ \\
& Epicatechin (ec) & $806 \pm 8.1$ \\
& B1 (cat-ec) & $66 \pm 1.3$ \\
& B2 (ec-ec) & $130 \pm 23.1$ \\
& & $300^{*} \pm 0.0$ \\
\hline
\end{tabular}

${ }^{*}$ Total phenolic content (mg GAE/L).

Epicatechin and catechin were the major identified compounds, while homovanillic, vanillic and gallic acid were the most abundant within phenolic acids. The total phenolic compounds in the grape extract were quantified in $300 \mathrm{mg}$ GAE/L. Vanillic and gallic acid moieties have been associated before with a loss of cytoplasmic membrane integrity, with the resultant loss of ion gradients, $\mathrm{pH}$ homeostasis and inhibition of respiratory activity [27]. On the other hand, the mechanisms of action proposed for the antibacterial activity of catechins have been mainly attributed to cytoplasmic membrane damage, although other mechanisms could be involved [28].

With the purpose to evaluate the impact of the phenolic compounds presented in the extract in the observed behavior, the pure phenolic compounds identified as part of the most active extract (homovanillic acid, vanillic acid, gallic acid, protocatechuic acid, clorogenic acid, phidroxibenzoic acid, catechin, epicatechin, and procyanidin dimmers B1 and B2) were tested against $C$. jejuni LP1 and results are shown in Table 7. Phenolics acids were the most active of the assayed compounds, provoking a growth decrease between 6.7 and $7.6 \mathrm{log}$, while epicatechin was the only flavanol with activity as pure compound $(1 \mathrm{log})$. These results show the contribution of phenolic acids to the inhibition of Campylobacter growth, although as part of the extract, additive and/or synergistic effects could be involved in the behavior observed in the case of the grape extract. This fact was previously described by us for the GSE extract [12] and others are observed a similar behavior for some catechins [28] and for phenolic acids such as gallic acid [29].

\section{Conclusion}

In summary, the results obtained in this work indicate that grape extracts could be an important source of phenolic compounds potentially active against Campylobacter. The grape extract assayed has been demonstrated to be useful against Campylobacter strains with multiple antibiotic resistances. Phenolic acids have been identified as 
Table 7. Effect of the standard phenolic compounds on the growth of $C$ jejuni LP1. All the compounds were tested at 1 $\mathrm{mg} / \mathrm{ml}$, except B1 and B2, which activity was assayed at 0.5 $\mathrm{mg} / \mathrm{ml}$. The results are expressed in $\mathrm{Log} \mathrm{UFC} / \mathrm{mL} \pm$ standard deviation (SD) $(n=2)$.

\begin{tabular}{|c|c|c|c|c|}
\hline \multicolumn{5}{|c|}{ Median $\log$ CFU/ml \pm SD $(\log$ reduction $)(n=2)$} \\
\hline Family & Compound & Control & $\begin{array}{l}\text { Compound } \\
\text { Activity }\end{array}$ & $\begin{array}{c}\text { Log of } \\
\text { Inhibition }\end{array}$ \\
\hline \multirow[t]{2}{*}{ Flavonols } & $\begin{array}{l}\text { Quercetin-3 } \\
\text {-glucoside }\end{array}$ & $8.28 \pm 0.0$ & $8.28 \pm 0.0$ & $\mathrm{NI}^{* *}$ \\
\hline & Quercetin & $8.28 \pm 0.0$ & $8.28 \pm 0.0$ & NI \\
\hline \multirow[t]{7}{*}{$\begin{array}{l}\text { Phenolic } \\
\text { Acids }\end{array}$} & $\begin{array}{l}\text { Homovanillic } \\
\text { Acid }\end{array}$ & $8.36 \pm 0.1$ & $>1.48 \mathrm{a}^{*} \pm 0.0$ & 6.88 \\
\hline & Vanillic Acid & $9.10 \pm 0.1$ & $>1.48 \mathrm{a} \pm 0.0$ & 7.62 \\
\hline & Gallic Acid & $8.15 \pm 0.0$ & $>1.48 \mathrm{a} \pm 0.0$ & 6.70 \\
\hline & $\begin{array}{l}\text { Protocatechuic } \\
\text { Acid }\end{array}$ & $8.78 \pm 0.0$ & $8.77 a \pm 0.1$ & NI \\
\hline & Chlorogenic Acid & $8.20 \pm 0.1$ & $8.17 \mathrm{a} \pm 0.1$ & NI \\
\hline & $\begin{array}{l}\text { p-hidroxibenzoic } \\
\text { Acid }\end{array}$ & $8.15 \pm 0.1$ & $>1.48 \mathrm{a} \pm 0.0$ & 6.67 \\
\hline & Sinapic Acid & $8.40 \pm 0.0$ & $8.42 \pm 0.2$ & NI \\
\hline \multirow[t]{4}{*}{ Catechins } & Catechin (cat) & $8.31 \pm 0.1$ & $8.84 \pm 0.1$ & NI \\
\hline & Epicatechin (ec) & $8.31 \pm 0.1$ & $7.27 \mathrm{a} \pm 0.0$ & 1.04 \\
\hline & B1 (cat-ec) & $8.21 \pm 0.1$ & $8.61 \pm 0.1$ & NI \\
\hline & B2 (ес-ес) & $8.21 \pm 0.1$ & $8.20 \pm 0.1$ & NI \\
\hline
\end{tabular}

${ }^{*}$ Calculated log of detection limit (30 CFU per plate). ${ }^{* *}$ NI: no growth inhibition. a Significantly different with respect to the growth control $(\mathrm{p} \leq 0.05)$.

the main compounds related with the behavior observed, and they are usually the main phenolics in grape and grape-derived products [30], constituting an important metabolite derived from the metabolism of more complex phenolic compounds, such as anthocyanins [31]. This fact could contribute to standardizing the production process of grape extracts to inhibit Campylobacter growth.

\section{Acknowledgements}

This work was founded through Projects AGL 200907894 from the MICINN, CSD2007-00063FUN-C-FOOD and BIOCAMP (CONSOLIDER INGENIO 2010).

\section{REFERENCES}

[1] M. Ganan, J. M. Silvan, A. V. Carrascosa and A. J. Martinez-Rodriguez, “Alternative Strategies to Use Antibiotics or Chemical Products for Controlling Campylobacter in the Food Chain,” Food Control, Vol. 24, 2012, pp. 6-14. http://dx.doi.org/10.1016/j.foodcont.2011.09.027

[2] C. Fitzgerald, J. Whichard and I. Nachamkin, "Diagnosis and Antimicrobial Susceptibility of Campylobacter Species,” In: I. Nachamkin, C. M. Szymanski and M. J. Blas- er, Eds., Campylobacter, 3rd Edition, American Society for Microbiology, Washington DC, 2008, pp. 227-243.

[3] T. Humphrey, S. O’Brien and M. Madsen, "Campylobacters as Zoonotic Pathogens: A Food Production Perspective," International Journal of Food Microbiology, Vol. 117, 2007, pp. 237-257.

http://dx.doi.org/10.1016/j.ijfoodmicro.2007.01.006

[4] C. K. Olson, S. Ethelberg, W. van Pelt and R. V. Tauxe, "Epidemiology of Campylobacter jejuni Infections in Industrialized Nations Campylobacter,” In: I. Nachamkin, C. M. Szymanski and M. J. Blaser, Eds., Campylobacter, 3rd Edition, American Society for Microbiology, Washington DC, 2008, pp. 163-189.

[5] Q. Zhang and P. J. Plummer, "Mechanisms of Antibiotic Resistance in Campylobacter," In: I. Nachamkin, C. M. Szymanski and M. J. Blaser, Eds., Campylobacter, 3rd Edition, American Society for Microbiology, Washington DC, 2008, pp. 263-266.

[6] EFSA, "The Community Summary Report on Trends and Sources of Zoonoses, Zoonotic Agents and Food-Borne Outbreaks in the European Union in 2008,” EFSA Journal, Vol. 8, 2010, p. 1496.

[7] European Commission, "Regulation (EC) No 1831/2003 on Additives for Use in Animal Nutrition," Official Journal of the European Union, Vol. L268, 2003, pp. 29-43.

[8] M. Anastasiadi, N. G. Chorianopoulos, G. J. E. Nychas and S. A. Haroutounian, "Antilisterial Activities of Polyphenolic-Rich Extracts of Grapes and Vinification Byproducts," Journal of Agricultural and Food Chemistry, Vol. 57, 2009, pp. 457-463.

http://dx.doi.org/10.1021/jf8024979

[9] J. D. Adamez, E. G. Samino, E. V. Sanchez and D. Gonzalez-Gomez, "In Vitro Estimation of the Antibacterial Activity and Antioxidant Capacity of Aqueous Extracts from Grape-Seeds (Vitis vinifera L.),” Food Control, Vol. 24, 2012, pp. 136-141.

http://dx.doi.org/10.1016/j.foodcont.2011.09.016

[10] V. Katalinic, S. Možina, I. Generaliz, D. Skroza, I. Ljubenkov and A. Klančnik, "Phenolic Profile, Antioxidant Capacity, and Antimicrobial Activity of Leaf Extracts from Six Vitis vinifera L. Varieties," International Journal of Food Properties, Vol. 16, 2013, pp. 45-60. http://dx.doi.org/10.1080/10942912.2010.526274

[11] M. Kurinčič, A. Klančnik and S. Možina, "Epigallocatechin Gallate as a Modulator of Campylobacter Resistance to Macrolide Antibiotics," International Journal of Antimicrobial Agents, Vol. 40, 2012, pp. 467-471. http://dx.doi.org/10.1016/j.ijantimicag.2012.07.015

[12] J. M. Silvan, E. Mingo, M. Hidalgo, S. de Pascual-Teresa, A. V. Carrascosa and A. J. Martinez-Rodriguez, "Antibacterial Activity of a Grape Seed Extract and Its Fractions against Campylobacter spp,” Food Control, Vol. 29, 2013, pp. 25-31. http://dx.doi.org/10.1016/i.foodcont.2012.05.063

[13] Clinical and Laboratoy Standars Institute (CLSI, formerly NCCLS), "Performance Standards for Antimicrobial Susceptibility Testing," Seventeenth Informational Supplement, Vol. 27, No. 1, 2007, pp. M100-S17.

[14] T. Luangtongkum, T. Y. Morishita, A. B. El-Tayeb, A. J. 
Ison and Q. Zhang, "Comparison of Antimicrobial Susceptibility Testing of Campylobacter spp. by the Agar Dilution and the Agar Disk Diffusion Methods,” Journal of Clinical Microbiology, Vol. 45, 2007, pp. 590-594. http://dx.doi.org/10.1128/JCM.00986-06

[15] J. K. Miflin, J. M. Templeton and P. J. Blackall, “Antibiotic Resistance in Campylobacter Jejuni and Campylobacter coli Isolated from Poultry in the South-East Queensland Region," Journal of Antimicrobial Chemotherapy, Vol. 59, 2007, pp. 775-778. http://dx.doi.org/10.1093/jac/dkm024

[16] K. Pallauf, J. C. Rivas-Gonzalo, M. D. del Castillo, M. P. Cano and S. de Pascual-Teresa, "Characterization of the Antioxidant Composition of Strawberry Tree (Arbutus unedo L.) Fruits," Journal of Food Composition and Analysis, Vol. 21, 2008, pp. 273-281. http://dx.doi.org/10.1016/j.jfca.2007.11.006

[17] B. M. Schmidt, J. W. Erdman and M. A. Lila, "Effects of Food Processing on Blueberry Antiproliferation and Antioxidant Activity," Journal of Food Science, Vol. 70, 2005, pp. S389-S394. http://dx.doi.org/10.1111/j.1365-2621.2005.tb11461.x

[18] M. Avila, M. Hidalgo, C. Sánchez-Moreno, C. Pelaez, T. Requena and S. de Pascual-Teresa, "Bioconversion of Anthocyanin Glycosides by Bifidobacteria and Lactobacillus,” Food Research International, Vol. 42, 2009, pp. 1453-1461.

http://dx.doi.org/10.1016/j.foodres.2009.07.026

[19] E. C. Gaynor, S. Cawthraw, G. Manning, J. K. MacKichan, S. Falkow and D. G. Newell, "The Genome-SeQuenced Variant of Campylobacter jejuni NCTC 11168 and the Original Clonal Clinical Isolate Differ Markedly in Colonization, Gene Expression, and Virulence-Associated Phenotypes,” Journal of Bacteriology, Vol. 186, 2004, pp. 503-517. http://dx.doi.org/10.1128/JB.186.2.503-517.2004

[20] S. S. Kim, H. S. Lee, Y. S. Cho, Y. S. Lee, C. S. Bhang, H. S. Chae, S. W. Han, I. S. Chung and D. H. Park, "The Effect of the Repeated Subcultures of Helicobacter pylori on Adhesion, Motility, Cytotoxicity, and Gastric Inflammation," Journal of Korean Medical Science, Vol. 17, 2002, pp. 302-306.

[21] A. Gibreel and D. E. Taylor, "Macrolide Resistance in Campylobacter jejuni and Campylobacter coli," Journal of Antimicrobial Chemotherapy, Vol. 58, 2006, pp. 243255. http://dx.doi.org/10.1093/jac/dkl210

[22] A. J. Hakanen, M. Lehtopolku, A. Siitonen, P. Huovinen, Kotilainen, "Multidrug Resistance in Campylobacter jejuni Strains Collected from Finnish Patients during 19952000," Journal of Antimicrobial Chemotherapy, Vol. 2, 2003, pp. 1035-1039. http://dx.doi.org/10.1093/jac/dkg489

[23] M. J. Blaser and J. Engberg, "Clinical Aspects of Campylobacter jejuni and Campylobacter coli Infections,” In: I. Nachamkin, C. M. Szymanski and M. J. Blaser, Eds., Campylobacter, 3rd Edition, American Society for Microbiology, Washington DC, 2008, pp. 99-121.

[24] M. Friedman, P. R. Henika, C. E. Levin, R. E. Mandrell and N. Kozukue, "Antimicrobial Activities of Tea Catechins and Theaflavins and Tea Extracts against Bacillus cereus," Journal of Food Protection, Vol. 69, 2006, pp. 365-361.

[25] H. Nawaz, J. Shi, G. Mittal and Y. Kakuda, "Extraction of Polyphenols from Grape Seeds and Concentration by Ultrafiltration," Separation and Purification Technology, Vol. 48, 2006, pp. 176-181. http://dx.doi.org/10.1016/j.seppur.2005.07.006

[26] J. L. Ríos and M. C. Recio, "Medicinal Plants and Antimicrobial Activity,” Journal of Ethnopharmacology, Vol. 100, 2005, pp. 80-84 http://dx.doi.org/10.1016/j.jep.2005.04.025

[27] M. Ravichandran, N. S. Hettiarachchy, V. Ganesh, S. C. Ricke and S. Singh, "Enhancement of Antimicrobial Activities of Naturally Occurring Phenolic Compounds by Nanoscale Delivery against Listeria monocytogenes, Escherichia coli O157:H7 and Salmonella typhimurium in Broth and Chicken Meat System,” Journal of Food Safety, Vol. 31, 2011, pp. 462-471. http://dx.doi.org/10.1111/j.1745-4565.2011.00322.x

[28] T. P. T. Cushnie and A. J. Lamb, "Recent Advances in Understanding the Antibacterial Properties of Flavonoids,” International Journal of Antimicrobial Agents, Vol. 38, 2011, pp. 99-107. http://dx.doi.org/10.1016/j.ijantimicag.2011.02.014

[29] M. J. R. Vaquero, P. A. A. Fernandez, M. C. M. de Nadra and A. M. S. de Saad, "Phenolic Compound Combinations on Escherichia coli Viability in a Meat System,” Journal of Agricultural and Food Chemistry, Vol. 58, 2010, pp. 60486052. http://dx.doi.org/10.1021/jf903966p

[30] M. Monagas, B. Bartolome and C. Gomez-Cordoves, "Updated Knowledge about the Presence of Phenolic Compounds in Wine," Critical Reviews in Food Science and Nutrition, Vol. 45, 2005, pp. 85-118. http://dx.doi.org/10.1080/10408690490911710

[31] T. Nurmi, J. Mursu, M. Heinonen, A. Nurmi, R. Hiltunen and S. Voutilainen, "Metabolism of Berry Anthocyanins to Phenolic Acids in Humans,” Journal of Agricultural and Food Chemistry, Vol. 57, 2009, pp. 2274-2281. http://dx.doi.org/10.1021/jf8035116 